\title{
Assessment of Acacia auriculiformis cunn. ex benth. seed germination and growth resistance towards arsenic toxicity
}

\begin{abstract}
Aim: Assess the ability of A. auriculiformis to resist arsenic (As) toxicity during germination and growth. Place and Duration of Study: The study was conducted in Department of Biology, Universiti Putra Malaysia Serdang, between September 2016 and May 2017. Methodology: A. auriculiformis seeds were germinated in series of As solutions (50 ppm-100 ppm). Each As concentration contained three replicates and each replicate contained ten seeds. After 15 days, germination analysis such as germination percentage, seedling vigor index, relative injury rate and mean germination time were calculated. Meanwhile, another set of A. auriculiformis's seeds were germinated using distilled water and planted in soil treated with different As concentration. After 60 days, the plant morphology, chlorophyll content and growth rate were also recorded. Results: The result revealed that, seed germination percentage, seedling vigor index and relative injury rate were significantly reduced at $80-100 \mathrm{ppm}$ As concentration, but the mean germination time showed no significant difference between controlled and treated seeds. The growth analysis showed that growth rate and chlorophyll content of treated plants decreased as much as $63.7 \%$ and $76.1 \%$ respectively. However, all the plants were able to survive up to $100 \mathrm{ppm}$ exposure. Conclusion: Therefore, it can be concluded that A. auriculiformis is capable to resist As contamination during germination and growth, thus showing the potential of species to remove As from soil, as a phytoremediator.
\end{abstract}

Keyword: Heavy metal; Height; Resistance; Seedling; Chlorophyll 